\title{
Psychiatry in Rotterdam's University Hospital
}

\author{
Annie Hall and John R. Robertson
}

Following a vist to the Royal College of Psychiatrists by Professor W. J. Schudel, It was decided to vist the Netherlands with a view to gathering information about the organisation of postgraduate medical education in poychiatiy there. Several Dutch poychiatrists were interviewed during the visit. The 'Colman' Report recommends limiling the period of training for Brtilish trainees. Formative methods of assessment are to be introduced, with a review of progress at regular intervals. The present Dutch system relles solely upon formattve assessment.

Taxation in Holland is greater than in the UK (60\% in the highest band), which might explain why psychiatry is much better resourced. The budget for psychiatry is divided three ways between hospitals, community psychiatry and hostels. The move into the community is also occurring, but at a slower rate than in the UK. Psychiatrists see more neurotic disorders and personality disorders in daily practice than is usual in the UK. Dutch psychiatrists have resisted division into sub-specialities, preferring to remain generalists. They may choose to practise in an area of special interest, and, apart from child psychiatry, all psychiatrists receive the same Certificate of Completion of Specialist Training (CCST). Child psychiatrists do a further year in their speciality for which they receive an additional certificate in child psychiatry. Continuing Professional Development (CPD) will be introduced in 1996.

\section{Dijkeigt Hospital}

Due to time constraints, it was only possible to visit one hospital. Dijkzigt Hospital in Rotterdam is a 90-bed Academic Unit situated within a large District General Hospital and divided into 3 wards of 30 beds each. There is a spacious Mother and Baby Unit with five cots. Three seclusion rooms are provided, fitted with reinforced plastic window panes. Each has a stout bed in the middle equipped with straps and buckles for physical restraint. There are extensive occupational therapy (OT) facllities in a separate annexe, offering arts and craft work as well as various rooms for group meetings. The accommodation for patients is of a high standard although patients are required to share their bedrooms with one or two others. The general state of cleanliness and orderliness was excellent, and there was little evidence of high levels of disturbance from patients at the time of our visit. No patients were in seclusion although staff reported quite frequent use of the seclusion facilities. At the time of the visit, bed occupancy was roughly $80 \%$. The range of diagnoses was much the same as in the UK with the majority of patients suffering from functional psychoses.

\section{Workload}

Permanent psychiatric staff (consultants) are assigned either to in-patients or out-patients. The in-patient unit takes $400-425$ admissions per year with an average 60-65 day length of stay. Bed occupancy averages $84 \%$ year round. The out-patient unit has 600-658 new referrals per year, which is more than 10 per week. There are 6500 patient contacts per year, which is 125 per week. Liaison referrals average more than the outpatients with 700-800 new referrals per annum or between 13 and 15 new referrals per week. Medical staff for all these services is provided by 11 consultants and 12 trainees. Each educational supervisor (consultant) attached to the in-patient unit has responsibility for 10-15 beds (rarely fully occupied), with one designated trainee as the ward doctor for those beds.

\section{Postgraduate training in psychiatry in The Netherlands}

Once accepted onto a scheme, training is highly structured with three years spent in general psychiatry, of which 12-18 months are spent in out-patient clinics. Six months are spent in community psychiatry and a further 12 months in elective placements of the trainees' choice.

No distinction is made between basic and higher specialist training. Progress through the 
scheme is based on an apprenticeship model with much dependence for quality and content of training placed upon the educational supervisors. There is no exit examination.

Psychiatric services in The Netherlands are increasingly based upon District General Hospitals, University hospitals and communitybased units. Large mental hospitals will continue to exist but are being run down as in the UK. Nevertheless, there is no shortage of beds and more in-patient facilities are available per head of population than in the UK. Only 20 out of 40 psychiatric hospitals in The Netherlands have training status which enables them to take on psychiatric trainees. All other psychiatric services are provided by a large group of young 'pluripotential' doctors waiting for access to a training scheme in one of a number of specialities. Hence ward-based and out-patient services at the junior doctor level are generally not covered by approved psychiatric trainees. Acceptance onto an approved specialist course may take 18 months to four years or more, and is decided on the basis of competitive interviews taking past experience into consideration. Once in, however, the trainee's training time is heavily protected. They are shielded from an excessive clinical work-load and appear to enjoy a position and status roughly equivalent to that of senior registrars in the UK.

Four hours per week are spent on formal teaching, two hours of which are spent in tutorials in small group modules. Trainees are expected to prepare for these sessions and questions are asked to assess their knowledge. Lack of knowledge can be detected in this way. and consistent poor performance is noted. Regular assessments of progress are made and drawn to the trainee's attention. A further two hours are spent in theoretical courses in psychotherapy. Personal psychotherapy sessions are also required. Separate journal meetings are also held.

Interview-techniques training differs according to location. Formal teaching is given in the introductory period. On the spot supervision and training are the responsibility of the educational supervisor. Trainees have their own personal training files, verified by the educational supervisor, in which they record the patients they are seeing. These are submitted as part of the assessment process.

In Rotterdam University Hospital, trainees in psychiatry rotate between 10 consultants in three years of hospital training. At times, more than one consultant may be involved in an individual's training.

\section{Recommended minimum standards}

- Staff:trainee ratio in all training departments should be $1: 1$.

\section{Typical training experience}

Duration: Four years, six months

Schedule: Three years general psychiatry (including consultation/liaison psychiatry) (12-18 months out-patient clinics); six months community psychiatry; twelve months (or $2 \times 6$ ) elective(s)

- Four hours/week formal courses during the whole training period.

- Regular (weekly) personal supervision sessions, separate for clinical work and psychotherapy (1 hour).

- In-patient care: 10-15 patients in care of the trainee at any time.

- Theory and practice in psychotherapy (two different modes minimum) taught and supervised by registered psychotherapists, plus 50 sessions (minimum) of personal psychotherapy.

- Teaching and consultation in neurology and internal medicine should be well organised.

\section{Assessment of progress/development of trainee (Rotterdam)}

- Weekly hour of supervision with staffpsychiatrist(s).

- Flrst year: evaluation of progress in knowledge and personal growth every three months (by staff psychiatrists of the unit). Report to Head of Department.

- Three-four times a year general discussion/ assessment of individual trainees during a meeting of all psychiatrists.

- Head of the Department (also teaching director) evaluates progress after each report and makes a formal decision on continuation of training at the end of the first year.

- Training committee discuss all aspects of training and meets eight times a year.

- Quality of training programme is periodically (2-5 years) assessed by official body of the Central College of Medical Specialists.

\section{Formative assessment and bars to progress}

The principal burden of training lies with the educational supervisors. The CCMS has recently introduced a Supervisors' Training Course which is attended voluntarily.

Trainees who are not suitably competent are most usually barred in the first year. After this, trainees need the approval of the Head of 
Department before moving on to the next stage of training. At Rotterdam, a professor is involved in the appraisal of trainees from the beginning of their training. In the first year assessments are completed by the educational supervisors every three months, and thereafter at intervals of nine months. Having completed the first year satisfactorily, it is highly unlikely that a trainee will not complete training, but may be asked to extend training by repeating a year or more if it is thought necessary. At the end of the training period the trainee recetves a formal document of completion of training and is then eligible to take on a specialist post.

It must be noted, however, that trainees on formal training schemes are highly motivated and carefully selected individuals. Upon qualifying from medical school, junior doctors must seek experience in non-training grade posts prior to acceptance onto a scheme. They may approach a scheme and be offered acceptance several years in advance contingent upon collecting relevant experience in particular jobs. A significant number of doctors fail to achieve training in the scheme of their choice and many drop out, often going abroad to gain experience. The MRCPsych examination is recognised in The Netherlands.

\section{Rotations}

Trainees do not rotate in the manner which is usual in the UK, the principal change being between one in-patient firm and another, and one out-patient firm and another, together with some liaison experience. Rotations are usually quite small.

Typically a trainee in Dijkzigt would do the following: 9 months Unit 1 (in-patients); 9 months Unit 2 (in-patients): 9 months OPD $(80 \%)+$ Liaison (20\%); and 9 months OPD (50\%)+IP Unit 3 (50\%).

To cover absence or holidays by any one supervisor, a pair of trainees will usually share two educational supervisors, one principal and one secondary.

The trainees have a wide choice of elective experience which they can add to the above. making up a total of four and a half years in training. When this is satisfactorily completed, together with recommendations from their teaching department, the trainee is eligible for a CCST and specialist status.

\section{Educational supervisors}

Consultants wishing to join a training scheme are required to make application to the Central College of Medical Specialists for approval of their status as trainers, and to produce a job description for the proposed trainee. The unit or hospital where they work must also be seen as a suitable establishment for trainees. Most consultants in Holland are not educational supervisors, often because the hospitals or unit where they work are seen to be unsuitable. This particularly applies to the older mental hospitals.

\section{Summary}

Once accepted onto a scheme, training proceeds in many ways like a senior registrar in the UK. No examination exists, but vigorous formative assessment is carried out with potential bars if insufficient progress is being made. Educational time is heavily protected, and includes an extenstve training in psychotherapy including 50 sessions of personal psychotherapy.

Educational supervisors represent a minority of consultants and must be prepared to devote up to $25 \%$ of their weekly work schedule to provide education in all its aspects. Teacher/trainee ratio should be $1: 1$.

Holland is currently considering introducing an examination to augment its assessment procedures. The consultants and trainees interviewed expressed a preference for the introduction of a nationwide examination.

At present, research is not an essential prerequisite to attaining a training post or a consultant post in Holland, although there is an ongoing discussion about the merits of all trainees being involved in research.

Dutch trainees may feel frustrated by the time spent trying to get onto a local psychiatric training scheme, and many of them may try to come to UK-based schemes in order to get their MRCPsych. This allows them an opportunity to short-circuit the Dutch system and progress to consultant in the 'fast lane'. The Dutch recognise the MRCPsych as a postgraduate specialist qualification.

\section{Acknowledgements}

The authors would like to express their appreciation to Professor Schudel and his colleagues in The Netherlands. This visit was made possible by the kind donation of $\$ 400$ by Lundbeck Pharmaceuticals Limited and enabled the College to gather information regarding one of our European Union partners, as well as providing an opportunity to look at 'formative' assessment as carried out in The Netherlands.

Annie Hall, Collegiate Trainees' Committee Representative, Homerton Hospital, London E9; and John R. Robertson, Sub-Dean, Horton Hospital, Surrey KT19 8PZ 